\title{
Evaluation of Blood Pressure Control Medicines Using Health and Medical Checkup Data in Japan: Alternative Methods for Randomized Controlled Trials
}

\author{
Kazumitsu Nawata',2, Yoichi Sekizawa ${ }^{2}$, Moriyo Kimura ${ }^{3}$ \\ ${ }^{1}$ Graduate School of Engineering, University of Tokyo, Tokyo, Japan \\ ${ }^{2}$ Research Institute of Economy, Trade and Industry (RIETI), Tokyo, Japan \\ ${ }^{3}$ The Public Health Institute, Tokyo, Japan \\ Email: nawata@tmi.t.u-tokyo.ac.jp, sekizawa-yoichi@rieti.go.jp, kimuramoriyo@gmail.com
}

How to cite this paper: Nawata, K., Sekizawa, Y. and Kimura, M. (2018) Evaluation of Blood Pressure Control Medicines Using Health and Medical Checkup Data in Japan: Alternative Methods for Randomized Controlled Trials. Health, 10, 587-603.

https://doi.org/10.4236/health.2018.105047

Received: April 18, 2018

Accepted: May 21, 2018

Published: May 24, 2018

Copyright (c) 2018 by authors and Scientific Research Publishing Inc. This work is licensed under the Creative Commons Attribution International License (CC BY 4.0).

http://creativecommons.org/licenses/by/4.0/

\begin{abstract}
Background: Many people take medicines to control high blood pressure (BP), or hypertension. Randomized clinical trials (RCT) are usually used for the evaluation of effects of medicines. However, RCT have some serious problems. Data and Methods: We evaluated the effects of BP medicines in Japan using a dataset containing 113,979 cases. We employed four statistical methods in the analysis. First, we simply compared the systolic blood pressure (SBP) of individuals with and without BP medicines. We then used a regression model with a dummy variable, representing taking medicines or not. We replaced the dummy variable by its expected value, and estimated the regression model again. Finally, we selected individuals who had both taken and not taken medicines at different times. The effect of sample selection was also considered in the estimation. Results: For the simple comparison, SBP with BP medicines was $11 \mathrm{mmHg}$ higher than without medicines. In the next regression analysis, SBP with BP medicines was still $5 \mathrm{mmHg}$ higher. When the dummy variable was replaced by its expected value, SBP with medicines decreased by $7 \mathrm{mmHg}$. For individuals taking medicines at some times and not at others, SBP decreased by 9 and $8 \mathrm{mmHg}$ in models with and without a sample bias correction, respectively. Conclusion: The methods eliminated some problems of RCT and might be attractive. However, we obtained contradictory conclusions depending on the statistical methods employed, despite using the identical dataset. Statistical methods must be selected carefully to obtain a reliable evaluation. Limitations: The dataset was observatory, and the sample period was only 3 years.
\end{abstract}




\section{Keywords}

Blood Pressure, Hypertension, Effect of Medicine, Randomized Clinical Trial, Health and Medical Checkup

\section{Introduction}

The World Health Organization (WHO) [1] states that high blood pressure (BP), or hypertension, is one of the most important health factors. According to the Ministry of Health, Welfare, and Labor, medical expenditures for high BP and related diseases were 1.85 trillion yen, accounting for $4.36 \%$ of total medical expenditures (42.36 trillion yen) in fiscal year 2015 in Japan [2]. Moreover, hypertension increases the medical expenditures of patients with other diseases such as diabetes [3] [4] [5], reduces happiness and life satisfaction [6] [7], and the true cost of hypertension is considered to be much higher than the direct cost.

Many medicines for controlling high BP (hereafter, BP medicines) are widely used. Therefore, proper evaluation of the effects of these medicines is very important. For assessing quality trial designs, systematic reviews of randomized controlled trials (RCT) [8] are considered the most reliable method, followed by simple RCT, other controlled clinical trials, observational studies (cohort and case control), cases studies, anecdotes, and personal opinions [9]. In RCT, participants are randomly divided into two (or more) groups. One group is treated with the medication in question (treated group), and the other with a placebo or standard medicine (control group).

To control for the effects of participant characteristics, such as gender, age and health conditions, a large sample is often needed, especially for long-term trials. Although systematic reviews of RCT, which increase the number of participants by combining various studies, are one solution, the biases of each review must be considered. These include publication bias, where trials with positive results are more likely to be published than those with negative or questionable results [10] [11] [12]. Researchers themselves might not have strong incentives to publish when the expected results are not obtained [10]. Sponsor bias is also possible. Many studies are sponsored by the pharmaceutical companies that make the medical products, and bias toward the sponsor's products and conflicts of interest have been suggested [13] [14] [15]. In the worst case, researchers might be dishonest in conducting the trials, raising conflicts of interest.

The Diovan scandal is famous in Japan. Diovan is the name of the valsartan, a medicine widely used to treat hypertension, sold by Novartis Pharma, the Japanese subsidiary of Novartis International AG. RCT were conducted at five university hospitals to study the effects of valsartan on the cardiovascular and cerebrovascular risks of hypertensive patients. Initial publications emphasized the effectiveness of the medicine; however, fraud, improper treatment of obtained 
datasets, and conflicts of interest were subsequently revealed. Data were altered in favor of the medicine, and a company employee analyzed the data without divulging his true position. As a result, many papers published in international academic journals such as the European Heart Journal, Circulation, International Journal of Cardiology, American Journal of Cardiology and Lancet had to be retracted, and researchers were penalized [16] [17]. The Japanese Society of Hypertension issued a special report on the Diovan scandal [18], and Novartis Pharma itself had to make statements to restore its credibility [19].

Moreover, practices are often terminated in the early stages for various reasons [20], which can cause a termination (or endpoint) bias. These facts suggest that while systematic reviews of RCT can be useful, performing and evaluating RCT properly is not an easy task. Double-blind RCT, where both participants and researchers are unaware as to who is receiving prescribed medicines, are usually used. Numerous studies on treatments for hypertension and related diseases have been conducted by double-blind RCT [21]-[34]. However, ethical problems with double-blind RCT have also been widely discussed [35]-[45]. The major arguments are that the control group does not get the benefit of the medicine when it is effective, and the double-blind design does not allow rapid detection of adverse effects related to the study medicine [46]. Informed consent is very important for satisfying ethical requirements and protecting participants [47], but individuals might hesitate to take part in trials if they know that they might receive the placebo. As a result, there have been strong suspicions concerning reliability of findings [48] [49] [50] [51].

While RCT are a very important tool for evaluating the effectiveness of medicines, they are far from perfect. Therefore, different methods for verifying and evaluating costly and time-consuming RCT results are needed. In this paper, we propose methods to evaluate the effects of medicines that do not depend on RCT. In Japan, most employees 40 or older are required to have health and medical checkups once a year by the Industrial Safety and Health Act [52]. Private companies and central and local governments form health insurance associations for their workers. Health and medical checkup information, including BP and treatment with BP medicines [53]. Since the dataset is not intended to evaluate particular medicines, it is free from the various described biases. However, because the characteristics of the dataset are quite different from those collected by RCT, it must be analyzed with a great care. We consider four different statistical methods to analyze the effects of BP medicines.

\section{Data and Methods}

In this study, we analyzed an anonymized dataset of health checkups obtained from one health insurance society. The dataset includes BP levels and information about treatment with BP medicines. First, we compared the BP levels of two groups: those taking BP medicines (hereafter, with BP medicines), and those not taking them (without BP medicines). Individual characteristics and health con- 
ditions can affect BP levels. To control for these factors, a regression using a dummy variable for taking BP medicines (BP_medicine dummy) was conducted for the second stage. Next, the BP medicine dummy was replaced by its expected values in the regression model to deal with the endogeneity problem. Finally, we analyzed the data of individuals who took BP medicines during certain periods of time, and not other periods. In this model, sample selection bias [54] problems were considered.

\subsection{Data}

The dataset consisted of 113,979 health and medical checkup cases obtained from 48,022 individuals (all employees 40 or over and their family members (voluntary)) of the society for three fiscal years (April 2013 through March 2016). The dataset contained various health and medical information for individuals, including BP levels and treatments with BP medicines. For details of the dataset, see Nawata et al. [53] and Nawata and Kimura [3] [4] [55]. In this study, we considered only systolic BP (SBP) to simplify the argument.

\subsection{Methodology}

We began by comparing the SBP of two groups: those treated with BP medicines, and those not treated. As Nawata et al. [55] suggested, various factors, such as age, gender, eating habits, daily activities, smoking, drinking alcohol, and sleeping habits can affect BP levels. We therefore considered the following regression model to remove such effects. Let $B P \_$Medicine be a dummy variable that takes 1 if an individual took BP control medicines in that fiscal year and 0 otherwise, and $x$ be other explanatory variables. We considered the following regression model (Model 1),

$$
\begin{aligned}
& \qquad B P=\alpha B P \_ \text {Medicine }+x^{\prime} \beta+u \\
& x^{\prime} \beta \equiv \beta_{1}+\beta_{2} \text { Age }+\beta_{3} \text { Female }+\beta_{4} \text { Height }+\beta_{5} \text { BMI }+\beta_{6} \text { Anamnesis } \\
&+\beta_{7} \text { Eat_fast }+\beta_{8} \text { Late_Supper }+\beta_{9} \text { After_Supper }+\beta_{10} \text { No_Breakfast } \\
&+\beta_{11} \text { Exercise }+\beta_{12} \text { Daily_activity }+\beta_{13} \text { Walk_fast }+\beta_{14} \text { Smoke } \\
&+\beta_{15} \text { Alcofol_freq }+\beta_{16} \text { Alcohol_amount }+\beta_{17} \text { Sleep }+\beta_{18} \text { Trend } \\
&+\beta_{19} \text { Weight_year. }
\end{aligned}
$$

The other explanatory variables were Height $(\mathrm{cm}), B M I$ (body mass index), Anamnesis (1: with anamnesis; 0: otherwise), Eat_fast (1: eating faster than other people; 0: otherwise), Late_Supper (1: eating supper within 2 hours before bed 3 or more times a week; 0: otherwise), After_supper (1: eating snacks after supper 3 or more times a week, 0 : otherwise), No_breakfact (1: not eating breakfast 3 or more times a week; 0: otherwise), Exercise (1: exercising 30 minutes or more 2 or more times a week for more than a year; 0 otherwise), Daily_activity (1: doing physical activities [walking or equivalent] 1 hour or more daily, 0: otherwise), Walk_fast (1: walking faster than other people of similar age and same gender; 0: otherwise), Smoke (1: smoking; 0: otherwise), Alcohol_freq (0: not drinking al- 
cohol, 1: sometimes, 2: every day), Alcohol_amount (0: not drinking; 1: drinking less than $180 \mathrm{ml}$ of Japanese sake wine [percentage alcohol about $15 \%$ ] or equivalent in a day when drinking; 2: drinking 180 - $360 \mathrm{ml}$; 3: drinking $360-540 \mathrm{ml}$; 4: drinking $540 \mathrm{ml}$ or more); Sleep (1: sleeping well; 0: otherwise). Trend is the time trend by year, and given by (year of checkup-2013) and Weight_year (1: weight change of more than $3 \mathrm{~kg}$ from previous year; 0: otherwise).

Since individuals take BP medicines because their BP levels are high, the endogeneity problem could exist. Let $S B P^{*}$ be the unobserved SBP without BP medicines. An individual takes medicine if the $S B P^{*}$ is higher than a certain value, depending on individual characteristics. Since $S B P^{*}$ is not observable if an individual is taking BP medicines, we assume

$$
S B P^{*}=x^{\prime} \gamma^{*}+v_{1}
$$

and the critical value of taking BP medicine or not is given by

$$
\bar{S}=x^{\prime} \gamma^{* *}+v_{2} \text {. }
$$

An individual takes BP medicines if $Z=S B P^{*}-\bar{S} \geq 0$, and does not take it otherwise. Assuming the normality of error terms, we get

$$
\begin{aligned}
& \text { BP_Medicine }= \begin{cases}1 & \text { if } Z \geq 0 \\
0 & \text { otherwise }\end{cases} \\
& Z=S B P^{*}-\bar{S}=x^{\prime} \gamma+v, \\
& x^{\prime} \gamma \equiv \\
& \gamma_{1}+\gamma_{2} \text { Female }+\gamma_{3} \text { Height }+\gamma_{4} B M I+\gamma_{5} \text { Anamnesis }+\gamma_{6} \text { Eat_fast } \\
&+\gamma_{7} \text { Late_Supper }+\gamma_{8} \text { After_Supper }+\gamma_{9} \text { No_Breakfast }+\gamma_{10} \text { Exercise } \\
&+ \gamma_{11} \text { Daily_activity }+\gamma_{12} \text { Walk_fast }+\gamma_{13} \text { Smoke }+\gamma_{14} \text { Alcofol_freq } \\
&+\gamma_{15} \text { Alcohol_amount }+\gamma_{16} \text { Sleep }+\gamma_{17} \text { Trend }+\gamma_{18} \text { Weight_year. }
\end{aligned}
$$

Therefore, we get

$$
\mathrm{E}\left(B P \_ \text {Medicine }\right)=P(\text { BP_Medicine }=1)=P(Z \geq 0)=\Phi\left(x^{\prime} \gamma\right),
$$

where $\Phi$ is the distribution function of the standard normal distribution. Equation (4) and the expected values are calculated by the Probit maximum likelihood method. Replacing the BP_Medicine dummy by its expected value in Model 1 , we get the regression model (Model 2) given by

$$
S B P=\alpha \mathrm{E}(\text { BP_Medicine })+x^{\prime} \beta+\varepsilon,
$$

Since Model 2 does not satisfy the standard assumption of the ordinary regression model, White's method [56] is used to calculate the standard error [57].

The dataset contains the data of individuals who took BP medicines during certain periods of time, and not other periods. Therefore, we consider the model just using the dataset of these individuals (Model 3). As before, we have to consider individual characteristics and Model 3 is the same as Model 1 except we used a part of the dataset. Since only a part of the dataset is used, a bias due to selection of the dataset might exist. Therefore, we check the results by Heckman's sample selection bias model [54] (For details, see Appendix A). Since Heckman's two step estimator [54] sometimes behaves poorly [58] [59], we used 
the maximum likelihood method of EViews (V. 9).

\section{Results}

\subsection{Comparisons of BP Levels with and without BP Medicines}

Figure 1 shows the distributions of SBP levels with and without BP medicines. BP levels without BP medicines were lower than those with BP medicines. We excluded cases where BP values were too large or too small (over 300 and under 10 , respectively), and where information regarding BP medicines was not available, and thus considered 113,960 cases. The basic BP statistics and characteristics of the two groups are presented in Table 1.

The numbers of the cases were 95,551 and 18,409 without and with BP medicines, respectively. Means and standard deviations (SD) of SBP were 126.0 and $16.0 \mathrm{mmHg}$ without BP medicines and 134.8 and $15.91 \mathrm{mmHg}$ with BP medicines. The difference of the means was $11.2 \mathrm{mmHg}$. Under the null hypothesis, the means of two groups are equal, and the t-value becomes 86.88 and is rejected at any reasonable significance level, and SBP with BP medicines are higher than those without.

\subsection{Regression Analysis using BP_Medicine Dummy}

The previous results suggest that SBP of individuals with BP medicines are higher than those without. However, Nawata et al. [53] suggested, individual characteristics such as gender, age, and health conditions affect BP levels. The group with BP medicines might consist of individuals belonging to higher BP categories. To control for these effects, we use Model 1. Cases where body mass index (BMI) was too large (over 100) and BP values were too large or small (over 300 or under 10) were excluded, leaving 95,212 cases without missing values in any explanatory variables for the analysis. $15.8 \%$ took BP medicines. A summary of explanatory variables is presented in Table 2 and the results of the estimation are given in Table 3.

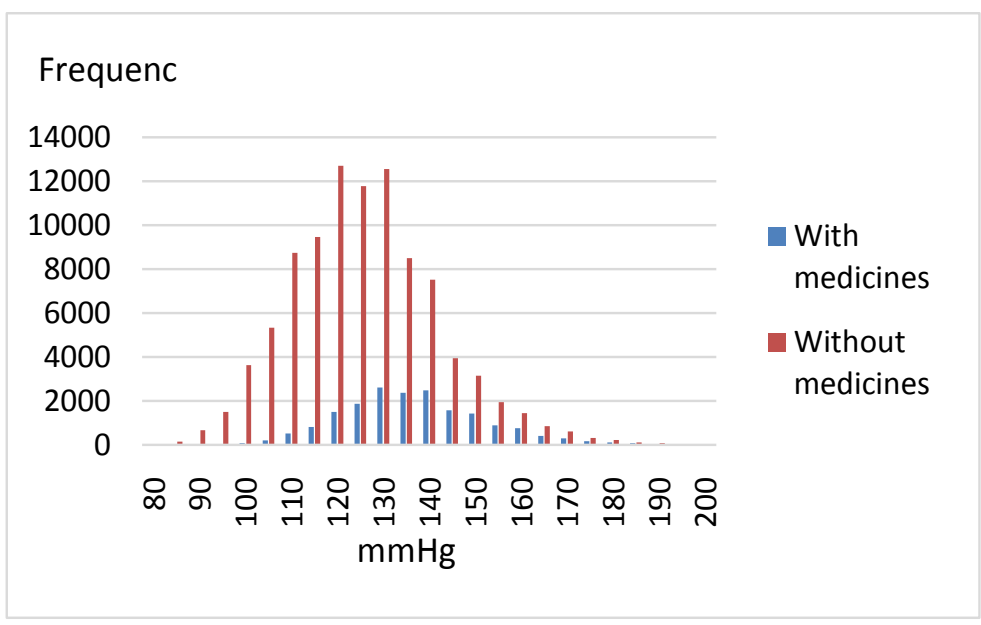

Figure 1. Distributions of SBP with and without BP medicines. 
Table 1. Basic statistics of SBP levels $(\mathrm{mmHg})$ and characteristics of two groups.

\begin{tabular}{ccc}
\hline & Without medicines & With medicines \\
\hline Mean & SBP & SBP \\
Median & 123.60 & 134.77 \\
Maximum & 123 & 134 \\
Minimum & 230 & 246 \\
SD & 67 & 81 \\
Age & 15.99 & 15.91 \\
Ratio of Female & $48.8(6.90)$ & $54.2(6.92)$ \\
Height (cm) & $48.80 \%$ & $12.40 \%$ \\
BMI & $167.37(8.04)$ & $167.48(7.53)$ \\
Ratio of Anamnesis & $23.3(3.54)$ & $25.8(4.17)$ \\
No. of Cases & $40.08 \%$ & $80.49 \%$ \\
\hline
\end{tabular}

SD: Standard deviation. Mean and SD (in the parentheses) are given for Age, Height and BMI.

Table 2. Summary of explanatory variables.

\begin{tabular}{cccc}
\hline Variable & \multicolumn{3}{c}{ Variable } \\
\hline Age & mean: 49.44, SD: 7.08 & Exercise & $1: 18.7 \%, 0: 81.3 \%$ \\
Female & $1: 22.9 \%, 0: 73.1 \%$ & Daily_activity & $1: 28.3 \%, 0: 71.7 \%$ \\
Height & mean: 167.32, SD: 8.01 & Walk_fast & $1: 40.1 \%, 0: 59.9 \%$ \\
BMI & mean: 23.71, SD: 3.74 & Smoke & $1: 38.7 \%, 0: 61.3 \%$ \\
Anamnesis & $1: 40.0 \%, 0: 51.0 \%$ & Alcohol_freq & $0: 35.0 \%, 1: 27.3 \%, 2: 37.6 \%$ \\
Eat_fast & $1: 31.8 \%, 0: 68.2 \%$ & Alcohol_amount & $0: 35.0 \%, 1: 22.5 \%, 2: 28.1 \%, 3:$ \\
Late_Supper & $1: 42.1 \%, 0: 57.9 \%$ & Sleep & $11.3 \%, 4: 3.1 \%$ \\
After_Supper & $1: 13.3 \%, 0: 86.7 \%$ & Weight_year & $1: 29.8 \%, 0: 70.2 \%$ \\
No_Breakfast & $1: 24.0 \%, 0: 76.0 \%$ & & \\
\hline
\end{tabular}

SD: Standard Deviation.

The estimate of BP_medicine is $5.1 \mathrm{mmHg}$ for Model 1 and the t-value is 34.82. Although the values are smaller (about half) those of the previous section, this means that the SBP of individuals with BP medicines are still higher than those without even when controlling for various individual factors. A direct interpretation might argue that BP medicines make BP levels higher and the medicines might be harmful (more than meaningless). However, individuals take BP medicines because their BP levels are high. There might be endogeneity of the BP_medicine dummy. In the next section, we consider the endogeneity problem.

\subsection{Regression Analysis Using Expected Value of BP_Medicine Dummy}

Equations (2)-(4) suggest that BP_medicine may be correlated with the error term of Equation (1). It is well known that the ordinary lease squares (OLS) 
Table 3. Results of estimation (Model 1).

\begin{tabular}{|c|c|c|c|}
\hline Variable & Estimate & SE & $\mathrm{t}$-value \\
\hline BP_medicine & 5.0542 & 0.1451 & $34.824^{\star *}$ \\
\hline Constant & 64.6157 & 1.6294 & $39.657^{\star *}$ \\
\hline Age & 0.4409 & 0.0075 & $58.915^{\star \star}$ \\
\hline Female & -2.79741 & 0.1720 & $-16.262^{\star *}$ \\
\hline Height & 0.0428 & 0.0085 & $5.011^{\star *}$ \\
\hline BMI & 1.2082 & 0.0143 & $84.542^{* *}$ \\
\hline Anamnesis & 0.5583 & 0.0999 & $5.590^{* *}$ \\
\hline Eat_fast & -0.4543 & 0.1070 & $-4.247^{\star *}$ \\
\hline Late_Supper & -0.1211 & 0.1039 & -1.166 \\
\hline After_Supper & -0.5871 & 0.1437 & $-4.086^{* *}$ \\
\hline No_Breakfast & 1.0547 & 0.1174 & $8.987^{\star *}$ \\
\hline Exercise & 0.0351 & 0.1312 & 0.267 \\
\hline Daily_activity & -0.3023 & 0.1137 & $-2.659^{\star *}$ \\
\hline Walk_fast & 0.1807 & 0.1013 & 1.784 \\
\hline Smoke & -0.3167 & 0.1054 & $-3.005^{\star *}$ \\
\hline Alcohol_freq & 1.7314 & 0.0883 & 19.610:: \\
\hline Alcohol_amount & 0.2611 & 0.0654 & $3.994^{* *}$ \\
\hline Sleep & 0.7767 & 0.1008 & $7.707^{\star \star}$ \\
\hline Trend & -0.0836 & 0.0564 & -1.482 \\
\hline Weight_year & -0.2732 & 0.1094 & $-2.496^{\star *}$ \\
\hline \multicolumn{2}{|c|}{ No. of Cases } & 95,212 & \\
\hline R2 & & 0.1910 & \\
\hline
\end{tabular}

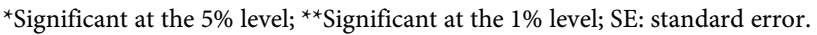

estimator is inconsistent in this situation. We therefore use the expected value instead of the original variables (Model 2), and obtain the consistent results presented in Table 4. (The results of probit maximum likelihood methods to calculate the expected values of $B P_{-}$medicine are given in Table 5.) In this model, the estimate of $\mathrm{E}$ (BP_medicine) is $-6.9 \mathrm{mmHg}$, and its $\mathrm{t}$-value is -9.279 ; that is, taking BP medicines reduced SBP significantly at any reasonable level, and results indicate that medicines were effective. Note that since the model contains various individual characteristics, this reduction was due to the medicines alone.

\subsection{Analyses Using the Data of Individuals Who Took BP Medicines in Some Periods and Not in Others}

If $\mathrm{BP}$ medicines are effective, SBP should be lower when individuals take BP medicines and higher when they do not. Therefore, we can evaluate the effects of BP medicines by analyzing SBP levels of individuals who took BP medicines in some sample periods and not in others. Since individual characteristics change every year (for example, age increases a year), we needed a regression analysis. The number of these cases was 4315 . 
Table 4. Results of estimation (Model 2).

\begin{tabular}{|c|c|c|c|}
\hline Variable & Estimate & SE & $\mathrm{t}$-value \\
\hline $\mathrm{E}$ (BP_medicine) & -6.8568 & 0.7390 & $-9.278^{\star *}$ \\
\hline Constant & 54.1126 & 1.7523 & $30.880^{* *}$ \\
\hline Age & 0.5881 & 0.0116 & $50.655^{\star *}$ \\
\hline Female & -3.22873 & 0.1785 & $-18.084^{* *}$ \\
\hline Height & 0.0307 & 0.0087 & $3.520^{\star *}$ \\
\hline BMI & 1.4687 & 0.0211 & $69.447^{\star *}$ \\
\hline Anamnesis & 2.2647 & 0.1407 & $16.092^{* *}$ \\
\hline Eat_fast & -0.2765 & 0.1064 & $-2.598^{\star *}$ \\
\hline Late_Supper & -0.0926 & 0.1037 & -0.893 \\
\hline After_Supper & -0.8699 & 0.1426 & $-6.099^{* *}$ \\
\hline No_Breakfast & 0.8252 & 0.1179 & $7.000^{* *}$ \\
\hline Exercise & -0.1188 & 0.1319 & -0.900 \\
\hline Daily_activity & -0.3289 & 0.1140 & $-2.884^{\star *}$ \\
\hline Walk_fast & -0.0157 & 0.1023 & -0.154 \\
\hline Smoke & -0.5081 & 0.1058 & $-4.802^{\star *}$ \\
\hline Alcohol_freq & 1.9426 & 0.0882 & $22.019^{\star *}$ \\
\hline Alcohol_amount & 0.4580 & 0.0656 & $6.982^{\star *}$ \\
\hline Sleep & 0.8233 & 0.1004 & $8.196^{* *}$ \\
\hline Trend & -0.1005 & 0.0567 & -1.771 \\
\hline Weight_year & -0.3331 & 0.1092 & $-3.050^{\star *}$ \\
\hline \multicolumn{2}{|c|}{ No. of Cases } & 95,212 & \\
\hline $\mathrm{R} 2$ & & 0.1814 & \\
\hline
\end{tabular}

${ }^{\star}$ Significant at the $5 \%$ level; ${ }^{*}$ Significant at the $1 \%$ level; SE: standard error.

The results of Model 3 using these data (Model 3 is the same as Model 1 except it uses a subset of the dataset) are presented in Table 6 . Since only a part of the dataset was used, a sample selection bias was possible. Therefore, the estimated results of Heckman's sample selection bias model by the maximum likelihood method are also presented in Table 6. Although results of some variables, such as anamnesis, are a bit different, the estimated values of $B P_{-}$medicine are similar using the two estimation methods. The estimates of $B P_{-}$medicine were SBP -9.2 and $-7.9 \mathrm{mmHg}$ in the OLS and sample selection bias model results, respectively. This implies that the BP medicines effectively reduced SBP by about 8 - 9 mmHg.

\section{Discussion}

RCT (especially double-blind RCT) is a very important and widely used tool to evaluate the effectiveness of medicines. However, such trials are costly and time consuming. At the development stage, pharmaceutical companies finance RCT, but once a medicine is approved for public use, finding private sponsors is not 
Table 5. Results of probit estimation (Equation (4)).

\begin{tabular}{|c|c|c|c|}
\hline Variable & Estimate & SE & $\mathrm{t}$-value \\
\hline Constant & -6.5528 & 0.1922 & $-34.095^{\star *}$ \\
\hline Age & 0.0625 & 0.0009 & $72.081^{\star *}$ \\
\hline Female & -0.26824 & 0.0213 & $-12.622^{\star *}$ \\
\hline Height & -0.0048 & 0.0010 & $-4.802^{\star *}$ \\
\hline BMI & 0.1071 & 0.0016 & $67.613^{\star *}$ \\
\hline Anamnesis & 0.7561 & 0.0119 & $63.414^{* *}$ \\
\hline Eat_fast & 0.0785 & 0.0123 & $6.356^{* *}$ \\
\hline Late_Supper & 0.0228 & 0.0120 & 1.895 \\
\hline After_Supper & -0.1385 & 0.0182 & $-7.624^{\star *}$ \\
\hline No_Breakfast & -0.1124 & 0.0143 & $-7.847^{\star *}$ \\
\hline Exercise & -0.0577 & 0.0154 & $-3.748^{\star *}$ \\
\hline Daily_activity & -0.0233 & 0.0135 & -1.722 \\
\hline Walk_fast & -0.0719 & 0.0120 & $-6.011^{* *}$ \\
\hline Smoke & -0.0708 & 0.0122 & $-5.814^{* *}$ \\
\hline Alcohol_freq & 0.0999 & 0.0101 & $9.849^{* *}$ \\
\hline Alcohol_amount & 0.0850 & 0.0073 & $11.679^{* *}$ \\
\hline Sleep & 0.0084 & 0.0119 & 0.706 \\
\hline Trend & -0.0071 & 0.0067 & -1.068 \\
\hline Weight_year & -0.0010 & 0.0127 & -0.080 \\
\hline \multicolumn{2}{|c|}{ No. of Cases } & 95,212 & \\
\hline \multicolumn{2}{|c|}{ Log likelihood } & $-31,761$ & \\
\hline
\end{tabular}

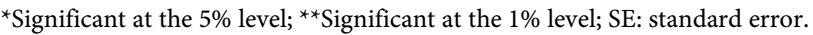

easy. Public funds are also limited, and researchers face difficulty performing further RCT. Moreover, as previously mentioned, there are biases and ethical problems with RCT. In other words, RCT is not a perfect method.

In this paper, we considered methods for evaluating the effects of BP medicines using the dataset of health and medical checkups done every fiscal year in Japan obtained from one health insurance society. The data collection method is completely different from that of RCT. Therefore, the dataset used was free from costs, long duration, and various biases and ethical problems.

However, data analyses must be conducted very carefully. Here, individuals were divided into two groups (with and without BP medicines) by a non-random method. Individuals with high $\mathrm{BP}$ would be more likely to take BP medicines. Accordingly, by a simple comparison, we found mean SBP with BP medicine group to be $11.2 \mathrm{mmHg}$ higher than that without BP medicine. Even when controlling for individual characteristics by regression analysis, the mean SBP with BP medicine group was still $5.1 \mathrm{mmHg}$ higher. This is considered to reflect the endogeneity of the BP_medicine dummy. We then sought to solve the problem by replacing the explanatory variable. Using the estimates of $\mathrm{E}$ 
Table 6. Results of estimation (Model 3).

\begin{tabular}{|c|c|c|c|c|c|c|}
\hline \multirow[b]{2}{*}{ Variable } & \multicolumn{3}{|c|}{ OLS } & \multicolumn{3}{|c|}{ Sample selection bias model } \\
\hline & Estimate & SE & $\mathrm{t}$-value & Estimate & SE & t-value \\
\hline BP_medicine & -9.1687 & 0.6028 & $-15.210^{\star *}$ & -7.9389 & 0.5789 & $-13.714^{\star *}$ \\
\hline Constant & 129.62 & 9.0517 & $14.320^{\star *}$ & -18.76 & 12.3630 & -1.517 \\
\hline Age & 0.1353 & 0.0433 & $3.120^{* *}$ & 0.6001 & 0.0543 & $11.050^{* *}$ \\
\hline Female & 1.87305 & 1.0876 & 1.722 & -2.4615 & 1.2998 & $-1.894^{\star *}$ \\
\hline Height & -0.0379 & 0.0472 & -0.803 & 0.0793 & 0.0572 & 1.386 \\
\hline BMI & 0.5800 & 0.0715 & $8.116^{* *}$ & 1.9653 & 0.1034 & $19.000^{* *}$ \\
\hline Anamnesis & -1.5499 & 0.5770 & $-2.686^{\star *}$ & 6.6617 & 0.7566 & $8.804^{\star *}$ \\
\hline Eat_fast & -1.3147 & 0.5783 & $-2.273^{\star}$ & -1.2730 & 0.7039 & -1.808 \\
\hline Late_Supper & -0.4998 & 0.5576 & -0.896 & 0.7738 & 0.6817 & 1.135 \\
\hline After_Supper & -1.2285 & 0.8434 & -1.457 & -1.6115 & 1.0152 & -1.587 \\
\hline No_Breakfast & 2.2474 & 0.6487 & $3.465^{* *}$ & 1.1213 & 0.7903 & 1.418 \\
\hline Exercise & -0.7250 & 0.7251 & -1.000 & -0.6602 & 0.8790 & -0.751 \\
\hline Daily_activity & -0.9962 & 0.6382 & -1.561 & -1.4352 & 0.7751 & -1.851 \\
\hline Walk_fast & 0.5329 & 0.5637 & 0.945 & 0.0771 & 0.6838 & 0.112 \\
\hline Smoke & 0.1673 & 0.5582 & 0.300 & 0.6163 & 0.6810 & 0.905 \\
\hline Alcohol_freq & 0.9684 & 0.4796 & $2.019^{\star}$ & 2.3773 & 0.5824 & 4.082 \\
\hline $\begin{array}{c}\text { Alco- } \\
\text { hol_amount }\end{array}$ & -0.0107 & 0.3375 & -0.032 & 0.9525 & 0.4119 & 2.312 \\
\hline Sleep & 0.4636 & 0.5614 & 0.826 & 0.7541 & 0.6808 & 1.107 \\
\hline Trend & -0.6515 & 0.3573 & -1.823 & -1.9750 & 0.4161 & $-4.746^{\star *}$ \\
\hline Weight_year & -1.3532 & 0.5834 & $-2.319^{* *}$ & -0.4481 & 0.7114 & -0.630 \\
\hline No. of Cases & & 4315 & & & & \\
\hline R2 & & 0.0965 & & & & \\
\hline
\end{tabular}

(BP_medicine), the expected value of BP_medicine was $-6.8 \mathrm{mmHg}$ and its $\mathrm{t}$-value was -9.28 , we found that BP medicines were effective in this model. This result is confirmed by the regression analyses of individuals who took BP medicines in some sample periods and not in others. SBP was reduced by $-9.2 \mathrm{mmHg}$ on average when BP medicines were taken by the OLS method. Since less than $4 \%$ of all cases were used in this analysis, it may have suffered from a sample selection bias. We obtained a similar estimated value $(-7.9 \mathrm{mmHg})$ by the Heckman's sample selection bias model, which implies the analysis was reliable.

\section{Conclusions}

In this paper, we consider a different approach to evaluate the effects of BP medicines. The dataset used was obtained from the health and medical checkups required of most employees aged 40 or over in Japan; thus, it was completely independent from direct measurements of the effects of medicines, and was not costly or time consuming to obtain. The results of the analyses are free from the various problems of (double-blind) RCT, such as cost, length of trial periods, 
various biases, sponsorship, and ethical issues.

Since the dataset was not designed to evaluate the effects of medicines, careful statistical methods were required. As shown in this paper, even though the same dataset was used, our results were contradictory depending on the analysis method. Only careful statistical approaches would verify the results of RCT. They could also help in the proper and effective design of RCT before the costly and time-consuming trials.

We considered only BP medicines, and the data were obtained for only three fiscal years from one health insurance society. To verify the method, it will be necessary to evaluate various medicines and treatments, and to collect more data for longer periods from various health insurance societies. We are currently negotiating with several health insurance societies to provide us their data. Developments of more reliable and standardized statistical methods might be necessary. These are subjects to be studied in future.

\section{Acknowledgements}

This study was supported by a Grant-in-Aid for Scientific Research, "Analyses of Medical Checkup Data and Possibility of Controlling Medical Expenses (Grant Number: 17H22509)", from the Japan Society of Science. This study was also conducted as a part of the Project "Exploring Inhibition of Medical Expenditure Expansion and Health-oriented Business Management Based on Evidence-based Medicine" undertaken at the Research Institute of Economy, Trade and Industry (RIETI). The dataset was anonymized at the health insurance society. This study was approved by the Institutional Review Boards of the University of Tokyo (number: KE17-30). The authors would like to thank the health insurance society for their cooperation in providing us the data. We would also like to thank an anonymous referee for his/her helpful comments and suggestions.

\section{References}

[1] World Health Organization (2018) Raised Blood Pressure. http://www.who.int/gho/ncd/risk_factors/blood_pressure_prevalence_text/en/

[2] Ministry of Health, Welfare, and Labor (2017) Heisei 27 Nendokokuminiryouhi No Gayou (Summary of National Medical Expenditures, Fiscal Year 2015). (In Japanese)

[3] Nawata, K. and Kimura, M. (2017) An Analysis of the Medical Costs of and Factors Affecting Diabetes Using the Medical Checkup and Payment Dataset in Japan: Can We Reduce the Prevalence of Diabetes? Health, 9, 1113-1127. https://doi.org/10.4236/health.2017.98081

[4] Nawata, K. and Kimura, M. (2017) Evaluation of Medical Costs of Kidney Diseases and Risk Factors in Japan. Health, 9, 1734-1749. https://doi.org/10.4236/health.2017.913127

[5] Codliffe, S. and Link, C.R. (2014) Racial Differences in the Effects of Hypertension and Obesity on Health Expenditures by Diabetes in the US. Applied Economics Letters, 21, 280-283. https://doi.org/10.1080/13504851.2013.856990

[6] Mojon-Azzi, S. and Sousa-Pazo, A. (2011) Hypertension and Life Satisfaction: An 
Analysis Using Data from the Survey of Health, Aging and Retirement in Europe. Applied Economics Letters, 18, 183-187. https://doi.org/10.1080/13504850903508291

[7] Joffres, M.R., Mamet, P., MacLean, D.R., et al. (2001) Distribution of Blood Pressure and Hypertension in Canada and the United States. American Journal of Hypertension, 14, 1099-1105. https://doi.org/10.1016/S0895-7061(01)02211-7

[8] Hansson, L.A., Zanchetti, A., Carruthers, S.G., et al. (1998) Effects of Intensive Blood-Pressure Lowering and Low-Dose Aspirin in Patients with Hypertension: Principal Results of the Hypertension Optimal Treatment (HOT) Randomised Trial. Lancet, 351, 1755-1762. https://doi.org/10.1016/S0140-6736(98)04311-6

[9] Greenhalgh, T. (2014) How to Read a Paper: The Basics of Evidence-Based Medicine. 5th Edition, Wiley Blackwell, Hoboken.

[10] Dickersin, K., Chan, S.S., Chalmersx, T.C., et al. (1987) Publication Bias and Clinical Trials. Controlled Clinical Trials, 8, 343-353. https://doi.org/10.1016/0197-2456(87)90155-3

[11] Hopewell, S., Loudon, K., Clarke, M.J., et al. (2009) Publication Bias in Clinical Trials Due to Statistical Significance or Direction of Trial Results (Review). John Wiley \& Sons, Hoboken.

http://sverigesradio.se/diverse/appdata/isidor/files/83/5775.pdf

[12] Turner, E.H., Matthews, A.M., Linardatos, E., et al. (2008) Selective Publication of Antidepressant Trials and Its Influence on Apparent Efficacy. New England Journal of Medicine, 358, 252-260. https://doi.org/10.1056/NEJMsa065779

[13] Lexchin, J., Bero, L.A., Djulbegovic, B. and Clark, O. (2003) Pharmaceutical Industry Sponsorship and Research Outcome and Quality: Systematic Review. BMJ, 326, 1167. https://doi.org/10.1136/bmj.326.7400.1167

[14] Perlis, R.H., Perlis, C.S., Wu, Y., et al. (2005) Industry Sponsorship and Financial Conflict of Interest in the Reporting of Clinical Trials in Psychiatry. American Journal of Psychiatry, 162, 1957-1960. https://doi.org/10.1176/appi.ajp.162.10.1957

[15] Lundh, A., Lexchin, J., Mintzes, B., et al. (2017) Industry Sponsorship and Research Outcome. Cochrane Database of Systematic Reviews. http://cochranelibrary-wiley.com/doi/10.1002/14651858.MR000033.pub3/full https://doi.org/10.1002/14651858.MR000033.pub3

[16] Kyoto Prefectural University of Medicine (2013) Research Report about the Kyoto Heart Study Clinical Study. (In Japanese)

[17] Ikei University School of Medicine (2013) About Retraction of Jikei Heart Study Paper. (In Japanese)

[18] Japanese Society of Hypertension (2013) Report of the Independent Committee for Clinical Trials. (In Japanese)

[19] Novartis Pharma (2018) For Restoring Credibility. (In Japanese) https://www.novartis.co.jp/about-us/credibility

[20] Pak, T.R., Rodriguez, M.D. and Roth, F.P. (2015) Why Clinical Trials Are Terminated. https://www.biorxiv.org/content/biorxiv/early/2015/07/02/021543.full.pdf

[21] Staessen, J.A., Fagard, R., Thijs, L., et al. (1997) Randomised Double-Blind Comparison of Placebo and Active Treatment for Older Patients with Isolated Systolic Hypertension. The Lancet, 350, 757-764. https://doi.org/10.1016/S0140-6736(97)05381-6

[22] Forette, F., Seux, M.L., Staessen, J.A., et al. (1998) Prevention of Dementia in Randomised Double-Blind Placebo-Controlled Systolic Hypertension in Europe 
(Syst-Eur) Trial. The Lancet, 352, 1347-1351.

https://doi.org/10.1016/S0140-6736(98)03086-4

[23] Brown, M.J., Palmer, C.R., Castaigne, A., et al. (2000) Morbidity and Mortality in Patients Randomised to Double-Blind Treatment with a Long-Acting Calcium-Channel Blocker or Diuretic in the International Nifedipine GITS Study: Intervention as a Goal in Hypertension Treatment (INSIGHT). The Lancet, 356, 366-372. https://doi.org/10.1016/S0140-6736(00)02527-7

[24] Simonneau, G., Barst, R.J., Galie, N., et al. (2002) Continuous Subcutaneous Infusion of Treprostinil, a Prostacyclin Analogue, in Patients with Pulmonary Arterial Hypertension: A Double-Blind, Randomized, Placebo-Controlled Trial. American Journal of Respiratory and Critical Care Medicine, 165, 800-804. https://doi.org/10.1164/ajrccm.165.6.2106079

[25] Lithell, H., Hansson, L., Ingmarb, S., et al. (2003) The Study on Cognition and Prognosis in the Elderly (SCOPE): Principal Results of a Randomized Double-Blind Intervention Trial. Journal of Hypertension, 21, 875-886. https://doi.org/10.1097/00004872-200305000-00011

[26] Julius, S., Kjeldsen, S.E., Weber, M., et al. (2004) Outcomes in Hypertensive Patients at High Cardiovascular Risk Treated with Regimens Based on Valsartan or Amlodipine: The VALUE Randomised Trial. The Lancet, 363, 2022-2031. https://doi.org/10.1016/S0140-6736(04)16451-9

[27] Philipp, T., Smith, T.R., Glazer, R., et al. (2007) Two Multicenter, 8-Week, Randomized, Double-Blind, Placebo-Controlled, Parallel-Group Studies Evaluating the Efficacy and Tolerability of Amlodipine and Valsartan in Combination and as Monotherapy in Adult Patients with Mild to Moderate Essential Hypertension. Clinical Therapeutics, 29, 563-580. https://doi.org/10.1016/j.clinthera.2007.03.018

[28] Oparil, S., Yarows, S.A., Patel, S., et al. (2007) Efficacy and Safety of Combined Use of Aliskiren And Valsartan in Patients with Hypertension: A Randomised, Double-Blind Trial. The Lancet, 370, 221-229. https://doi.org/10.1016/S0140-6736(07)61124-6

[29] Warwickm J., Falaschetti, E., Rockwood, K., et al. (2015) No Evidence That Frailty Modifies the Positive Impact of Antihypertensive Treatment in Very Elderly People: An Investigation of the Impact of Frailty upon Treatment Effect in the Hypertension in the Very Elderly Trial (HYVET) Study, a Double-Blind, Placebo-Controlled Study of Antihypertensives in People with Hypertension Aged 80 and over. BMC Medicine, 13, 78. https://doi.org/10.1186/s12916-015-0328-1

[30] Dower, J.I., Geleijnse, J.M., Gijsbers, L., et al. (2015) Supplementation of the Pure Flavonoids Epicatechin and Quercetin Affects Some Biomarkers of Endothelial Dysfunction and Inflammation in (Pre)Hypertensive Adults: A Randomized Double-Blind, Placebo-Controlled, Crossover Trial. Journal of Nutrition, 145, 1459-1463. https://doi.org/10.3945/jn.115.211888

[31] Weber, M.A., Mansfield, T.A. and Cain, V.A. (2016) Blood Pressure and Glycaemic Effects of Dapagliflozin versus Placebo in Patients with Type 2 Diabetes on Combination Antihypertensive Therapy: A Randomised, Double-Blind, Placebo-Controlled, Phase 3 Study. The Lancet Diabetes \& Endocrinology, 4, 211-220. https://doi.org/10.1016/S2213-8587(15)00417-9

[32] Brüll, B., Burak, C., Stoffel-Wagner, B., et al. (2017) Acute Intake of Quercetin from Onion Skin Extract Does Not Influence Postprandial Blood Pressure and Endothelial Function in Overweight-to-Obese Adults with Hypertension: A Randomized, Double-Blind, Placebo-Controlled, Crossover Trial. European Journal of Nutrition, 56, 1347-1357. https://doi.org/10.1007/s00394-016-1185-1 
[33] Juliene, G., Costa, J.G., Giolo, J.S., Mariano, I.M., et al. (2017) Combined Exercise Training Reduces Climacteric Symptoms without the Additive Effects of Isoflavone Supplementation: A Clinical, Controlled, Randomised, Double-Blind Study. Nutrition and Health, 23, 271-279. https://doi.org/10.1177/0260106017727359

[34] Behr, J., Nathan, S.D., Harari, S., et al. (2018) Sildenafil Added to Pirfenidone in Patients with Advanced Idiopathic Pulmonary Fibrosis and Risk of Pulmonary Hypertension: A Phase IIb, Randomized, Double-Blind, Placebo-Controlled Study-Rationale and Study Design. Respiratory Medicine.

[35] Rothman, K.J. and Michaels, K.B. (1994) The Continuing Unethical Use of Placebo Controls. New England Journal of Medicine, 331, 394-398.

https://doi.org/10.1056/NEJM199408113310611

[36] Clark, P.I. and Leaverton, P.E. (1994) Scientific and Ethical Issues in the Use of Placebo Controls in Clinical Trials. Annual Review of Public Health, 15, 19-38. https://doi.org/10.1146/annurev.pu.15.050194.000315

[37] Temple, R. and Ellenberg, S.S. (2000) Placebo-Controlled Trials and Active-Control Trials in the Evaluation of New Treatments: Part 1: Ethical and Scientific Issues. Annals of Internal Medicine, 133, 455-463. https://doi.org/10.7326/0003-4819-133-6-200009190-00014

[38] Ellenberg, S.S. and Temple, R. (2000) Placebo-Controlled Trials and Active-Control Trials in the Evaluation of New Treatments. Part 2: Practical Issues and Specific Cases. Annals of Internal Medicine, 133, 464-470. https://doi.org/10.7326/0003-4819-133-6-200009190-00015

[39] Simon, R. (2000) Are Placebo-Controlled Clinical Trials Ethical or Needed When Alternative Treatment Exists? Annals of Internal Medicine, 133, 474-475. https://doi.org/10.7326/0003-4819-133-6-200009190-00017

[40] Emanuel, E.J. and Miller, P.G. (2001) The Ethics of Placebo-Controlled Trials-A Middle Ground. New England Journal of Medicine, 345, 915-919. https://doi.org/10.1056/NEJM200109203451211

[41] Millum, J. and Grady, C. (2013) The Ethics of Placebo-Controlled Trials: Methodological Justifications. Contemporary Clinical Trials, 36, 510-514. https://doi.org/10.1016/j.cct.2013.09.003

[42] Ćurković, M., Živković, M., Radić, K., Maja, et al. (2015) Ethical Overview of Placebo Control in Psychiatric Research-Concepts and Challenges. Psychiatria Danubina, 27, 118-125.

[43] Levy, M. (2015) The Ethics of Placebo-Controlled Clinical Trials in NMO-A Balance of Risks. Multiple Sclerosis and Related Disorders, 4, 512-514.

https://doi.org/10.1016/j.msard.2015.07.016

[44] Cheah, P.Y., Steinkamp, N. and von Seidlein, L. (2018) The Ethics of Using Placebo in Randomised Controlled Trials: A Case Study of a Plasmodium Vivaxantirelapse Trial. BMC Medical Ethics, 19, 19. https://doi.org/10.1186/s12910-018-0259-4

[45] Skierka, A.S. and Michels, K.B. (2018) Ethical Principles and Placebo-Controlled Trials-Interpretation and Implementation of the Declaration of Helsinki's Placebo Paragraph in Medical Research. BMC Medical Ethics, 19, 24. https://doi.org/10.1186/s12910-018-0262-9

[46] Heckerling, P.S. (2005) The Ethics of Single Blind Trials. Ethics \& Human Research, 27, 12-16. https://doi.org/10.2307/3563956

[47] Appelbaum, P.S., Roth, L.H. and Lidz, C. (1982) The Therapeutic Misconception: Informed Consent in Psychiatric Research. Journal of Law and Psychiatry, 5, 319-329. https://doi.org/10.1016/0160-2527(82)90026-7 
[48] Spielmans, G.I. and Parry, P.I. (2010) From Evidence-Based Medicine to Marketing-Based Medicine: Evidence from Internal Industry Documents. Journal of Bioethical Inquiry, 7, 13-29. https://doi.org/10.1007/s11673-010-9208-8

[49] Greenhalgh, T., Howick, J. and Maskrey, N. (2014) Evidence Based Medicine: A Movement in Crisis? BMJ, 348, g3725. https://doi.org/10.1136/bmj.g3725

[50] Every-Palmer, S. and Howick, J. (2014) How Evidence-Based Medicine Is Failing Due to Biased Trials and Selective Publication. Journal of Evaluation Clinical Practice, 20, 908-914. https://doi.org/10.1111/jep.12147

[51] Fava, G.A. (2017) Evidence-Based Medicine Was Bound to Fail: A Report to Alvan Feinstein. Journal of Clinical Epidemiology, 84, 3-7. https://doi.org/10.1016/j.jclinepi.2017.01.012

[52] Japanese Law Translation (2009) Industrial Safety and Health Act. http://www.japaneselawtranslation.go.jp/law/detail/?id=1926\&vm=\&re

[53] Nawata, K., Matsumoto, A., Kajihara, K., et al. (2017) Evaluation of the Distribution of and Factors Affecting Blood Pressure Using Medical Checkup Data in Japan. Health, 9, 124-137. https://doi.org/10.4236/health.2017.91009

[54] Heckman, J. (1979) Sample Selection Bias as a Specification Error. Econometrica, 47, 153-161. https://doi.org/10.2307/1912352

[55] Nawata, K. and Kimura, M. (2017) Reliability of Blood Pressure Measurements: An Analysis of the White Coat Effect and Its Fluctuations. Health, 9, 506-519. https://doi.org/10.4236/health.2017.93036

[56] White, H. (1980) A Heteroskedasticity-Consistent Covariance Matrix Estimator and a Direct Test for Heteroskedasticity. Econometrica, 48, 817-838. https://doi.org/10.2307/1912934

[57] Amemiya, T. (1985) Advanced Econometrics. Harvard University Press, Cambridge.

[58] Nawata, K. (1993) A Note on Estimation of Models with Sample Selection Biases. Economic Letters, 42, 15-24. https://doi.org/10.1016/0165-1765(93)90167-B

[59] Nawata, K. (1994) Estimation of Sample Selection Bias Models by the Maximum Likelihood Estimator and Heckman's Two-Step Estimator. Economic Letters, 45, 33-40. https://doi.org/10.1016/0165-1765(94)90053-1 


\section{Appendix A: Heckman's Sample Selection Model}

To evaluate the effects of BP medicines using the data of individuals who took BP medicines in some sample periods and not in others, we considered the model,

$$
S B P=\alpha B P_{-} \text {Medicine }+x^{\prime} \beta+u .
$$

However, we used less than $4 \%$ of total cases for the estimation. This means that we might have selected special individuals. In this situation, Heckman's sample selection bias model [54] is widely used to verify the estimation results. We consider a latent variable $y^{*}$, and an individual takes BP medicines if

$$
y^{*} \geq 0, y^{*}=z^{\prime} \delta+w
$$

where $w$ is an error term with mean zero and variance $1, V(u)=\sigma^{2}$ and the correlation coefficient of $u$ and $w$ is $\rho$. For details of the model and likelihood function, see Amemiya [57] and Nawata [59]. The estimation results of the selection equation (Equation (8)) are given in Table A1. The estimate of the $\rho$ and $\mathrm{t}$-value are 0.926 and 117.08 , and the effect of sample selection bias considered in this model.

\begin{tabular}{|c|c|c|c|}
\hline Variable & Estimate & $\mathrm{SE}$ & $\mathrm{t}$-value \\
\hline Constant & -4.7304 & 0.2477 & $-19.100^{\star *}$ \\
\hline Age & 0.0182 & 0.0011 & $16.357^{\star \star}$ \\
\hline Female & -0.13696 & 0.0284 & $-4.823^{\star *}$ \\
\hline Height & 0.0042 & 0.0013 & $3.240^{* *}$ \\
\hline BMI & 0.0488 & 0.0020 & $24.836^{\star *}$ \\
\hline Anamnesis & 0.3058 & 0.0152 & $20.071^{\star \star}$ \\
\hline Eat_fast & -0.0068 & 0.0161 & -0.422 \\
\hline Late_Supper & 0.0534 & 0.0156 & $3.431^{\star *}$ \\
\hline After_Supper & -0.0163 & 0.0228 & -0.712 \\
\hline No_Breakfast & -0.0395 & 0.0180 & $-2.192^{\star}$ \\
\hline Exercise & -0.0028 & 0.0201 & -0.138 \\
\hline Daily_activity & -0.0105 & 0.0177 & -0.593 \\
\hline Walk_fast & -0.0282 & 0.0156 & -1.810 \\
\hline Smoke & 0.0455 & 0.0156 & $2.908^{\star *}$ \\
\hline Alcohol_freq & 0.0358 & 0.0132 & $2.718^{\star \star}$ \\
\hline Alcohol_amount & 0.0342 & 0.0094 & $3.635^{\star *}$ \\
\hline Sleep & 0.0228 & 0.0155 & 1.470 \\
\hline Trend & -0.0412 & 0.0087 & $-4.716^{* *}$ \\
\hline Weight_year & 0.0343 & 0.0163 & $2.104^{\star}$ \\
\hline$\sigma^{2}$ & 33.2937 & 0.9912 & $33.587^{\star *}$ \\
\hline$\rho$ & 0.9256 & 0.0079 & $117.08^{\star \star}$ \\
\hline
\end{tabular}

Table A1. Results of estimation: selection model (Equation (8)).

${ }^{\star}$ Significant at the $5 \%$ level; ${ }^{*}$ Significant at the $1 \%$ level; SE: standard error. 